\title{
POLÍTICAS PÚBLICAS PARA FORMAÇÃO DE PROFESSORES NO BRASIL:
}

formação ou conformação ao ideário do capital?

\author{
Julia Malanche ${ }^{1}$ \\ Rita de Cássia Duarte ${ }^{2}$
}

\begin{abstract}
RESUMO
A proposta desse artigo é analisar a política de formação destinada a professores que atuam na educação básica que nas últimas duas décadas vêm sendo oferecidas em sua maior parte pela iniciativa privada e via modalidade $\mathrm{EaD}$ (ensino a distância). Tendo por base os postulados do materialismo histórico e dialético contido na pedagogia histórico-crítica demarcamos nesse artigo a função social da escola, do professor e do currículo escolar no processo educativo. Asseveramos que as pedagogias hegemônicas que compõem o ideário pós-moderno, portanto, niilistas e pragmáticas ocupam os espaços acadêmicos e virtuais com teorias pedagógicas relativistas que privilegiam a adaptação dos indivíduos às exigências econômicas, políticas e culturais do capitalismo contemporâneo, comprometendo dessa maneira a formação docente.
\end{abstract}

Palavras-chave: pedagogia histórico-crítica. Formação de professores. Educação a distância. Teorias pedagógicas.

PUBLIC POLICIES FOR TEACHER TRAINING IN BRAZIL: formation or conformation to the ideals of capital?

\begin{abstract}
The purpose of this paper is to analyze the training policy aimed at teachers who work in basic education that in the last two decades have been offered mostly by private initiative and via distance education $(\mathrm{EaD})$ modality. Based on the postulates of historical and dialectical materialism contained in the historical-critical pedagogy, this paper point out a social function of the school, the teacher and the school curriculum in the educational process. We assert that the hegemonic pedagogies that make up the postmodern ideology, therefore, nihilistic and pragmatic occupy the academic and virtual spaces with relativistic pedagogical theories that privilege the adaptation of individuals to the economic, political and cultural demands of contemporary capitalism, thus compromising the formation teacher.
\end{abstract}

Keywords: Historical-critical pedagogy. Teacher training. Distance education. Pedagogical theories.

\section{INTRODUÇÃO}

A política de formação inicial de professores para atuarem na educação básica, segue sendo um tema importante no debate educacional, uma vez que existem divergências teóricas

\footnotetext{
${ }^{1}$ Doutora em Educação Escolar pela UNESP/Araraquara (2014). Pós-doutorado em Educação e Currículo no Institute of Education University College London em Londres no Reino Unido (2017-2018).

${ }^{2}$ Graduação em História licenciatura plena pelo Instituto Superior de Educação Ibituruna. Programa de Pósgraduação em Educação Escolar..
} 
a esse respeito entre os profissionais que pesquisam e debatem essa temática, além de ser alvo de constantes reformas por parte do Estado a partir de orientações de Organismos Internacionais $(\mathrm{OI})$.

O discurso corrente que perpassa ao da desvalorização da escola pública é de que muitos professores insistem em manter uma postura tradicional e de comando em sala de aula, são resistentes ao uso pedagógico das novas tecnologias e clássicos na seleção de conteúdos, já que esses de acordo com as pedagogias do aprender a aprender estão mortos e desconectados da vida cotidiana dos alunos e, portanto, sem utilidade para a resolução de dilemas da modernidade.

O fato é que essa discussão tem sido apresentada para população de forma tendenciosa pelos meios de comunicação que cumprem sistematicamente a tarefa de auxiliar na continua desinformação da população que ao reproduzirem o discurso raso de parlamentares, intelectuais orgânicos e de empresários vinculados a grandes grupos econômicos, desqualificam não só o trabalho dos professores como também o da escola pública enquanto centro de formação e humanização. E ao fazerem isso, de certa forma, legitimam a discussão sobre a privatização do ensino que pode vir a ocorrer de várias formas, "desde a iniciativa privada ofertar diretamente o serviço, como buscar que os próprios indivíduos financiem os seus estudos". (OLIVEIRA, 2004, p. 52-53).

Nesse processo, a escola é apresentada como instrumento de inserção dos indivíduos ao mercado de trabalho e descaracterizada quanto à sua finalidade educativa que partilhamos com a pedagogia histórico-crítica como sendo a de proporcionar a todos a apropriação dos conhecimentos científicos, artísticos e filosóficos, produzidos pela humanidade ao longo da história, e que na escola devem se fazer presente nos conteúdos escolares.

A campanha de desvalorização da escola pública fica ainda mais comprometida com a divulgação recente da pesquisa externa da $\mathrm{ANA}^{3}$ Inep/MEC/2018, que envolveu mais de 2 milhões de crianças que se encontravam na faixa etária de 8 anos de idade no ano de 2016, portanto cursando o ensino fundamental, divulgados pelo Jornal Folha de São Paulo de 18/03/2018 indicando que

em matemática 55\% dos alunos avaliados não resolvem contas de subtração que envolvem dois algarismos, já na escrita $34 \%$ não conseguem fazer uso adequado de pontuação de modo a comprometer uma narrativa". (SALDAÑA, 2018).

\footnotetext{
${ }^{3}$ Avaliação Nacional de Alfabetização
} 
Já em relação ao ensino médio os dados também registram resultados pífios, conforme indica as provas de avaliação nacionais e internacionais realizadas pelo "Programa Internacional de Avaliação de Alunos (Pisa, na sigla em inglês), principal pesquisa da educação mundial. O levantamento mostra que "quase 70\% dos alunos brasileiros entre 15 e 16 anos" encontra-se "abaixo do nível 2 em matemática - os níveis vão do 1 ao 6 . Apenas $0,8 \%$ deles atingiram o 5 ou 6" (SHALON, 2016).

Os números mostram que nossos alunos estão muito longe do desejável em termos de rendimento escolar, mas devemos ter cautela para não associá-los unicamente ao desempenho dos professores, desassociando-os da política educacional e do modelo de escola que esta sendo imposto aos sistemas de ensino no Brasil por meio das orientações pedagógicas aplicadas desde a década de 1990, no contexto da reforma do Estado e da educação de inspiração neoliberal e apoiada por organismos internacionais multilaterais tais como o Banco Mundial (BM) e UNESCO.

Observa-se que as campanhas de desmoralização da escola pública, bem como as propostas de reformas curriculares planejadas com o concurso de setores empresariais que expressam interesses privatistas na educação ${ }^{4}$, têm por objetivo limitar o saber elaborado, resultante do conhecimento historicamente produzido pela humanidade, ao uso restrito da burguesia. Utilizando-se como argumento,

de que eles seriam constituídos por "conteúdos prontos e acabados", coisas mortas, inertes, desconectados da vida dos alunos e opostos ao caráter ativo que deveria ter a aprendizagem. É nessa direção que a educação escolar recebe o adjetivo de "conteudista" e, em contraposição, é defendida uma educação pautada na vida, nos processos de construção do conhecimento e na realização de atividades voltadas para questões do cotidiano. Morte e vida, inércia e atividade, passado e presente, produto e processo são realidades consideradas de maneira isolada e antagônica por esse tipo de critica à escola. (DUARTE, 2016, p. 48).

Isto posto, não há interesse algum por parte do Estado em socializar o conhecimento objetivo, e consequentemente em investir em educação pública, e sim esvaziar a escola de conteúdos ${ }^{5}$ ou até mesmo em desmontá-la ou torná-la um nicho de mercado de exploração para os empresários da educação. Uma resposta positiva a essa tendência está sendo o de pressionar para que os cursos em nível superior que oferecem as licenciaturas os façam por

\footnotetext{
${ }^{4}$ Um exemplo é o grupo de empresários que formam o grupo Todos pela Educação e que financiaram a elaboração da Base Nacional Comum Curricular aprovada em 2017.

${ }^{5}$ Isso está refletido na Base Nacional Comum Curricular Comum 2017.
} 
meio do modelo EaD, onde também se observa o crescimento descomunal de universidades privadas nesse setor.

Nesse artigo, temos por intenção contribuir com a discussão sobre a política de formação docente inicial oferecida aos professores da rede pública, partindo do pressuposto de que esta formação deve ser de encargo do Estado. Em relação à formação inicial indicamos maior investimento dos cursos de licenciatura já existentes, bem como em criar novos cursos na modalidade presencial de modo a desestimular o setor educacional privado. Entendemos também que a formação continuada destes professores deva ser realizada em convênio com universidades públicas com projetos de formação por meio de atividades da extensão universitária.

Tomando por base teórico-metodológica a pedagogia histórico-critica, este artigo segue o seguinte ordenamento: a) O papel social do professor e do currículo escolar; b) As concepções pedagógicas hegemônicas em sintonia com o universo ideológico neoliberal c) A expansão da formação de professores via modalidade de EaD; d) Considerações finais.

\section{O PAPEL SOCIAL DA ESCOLA, DO PROFESSOR E DO CURRÍCULO ESCOLAR}

Entendemos que toda a ação educativa deve ser intencional e direcionada, e é indispensável para o processo de humanização e transformação social. No entanto sabemos que estando à ação educativa implantada na sociedade capitalista ela traz em seu cerne inúmeras contradições. Por um lado ela responde as necessidades da classe burguesa após a revolução industrial de formar mão de obra e simultaneamente estabelecer controle ideológico sobre esta mesma e por outro, expressa o anseio de socialização do saber elaborado com o intuito de elevação do espírito humano e de emancipação do gênero humano frente à natureza, conforme idealizavam os filósofos e educadores iluministas, constituindo-se, nesta perspectiva, numa conquista histórica de toda a humanidade. Concordamos com Martins, quando a mesma afirma que:

[...] o produto do trabalho educativo deve ser a humanização dos indivíduos, que, por sua vez, para se efetivar, demanda a mediação da própria humanidade dos professores. Conforme destacamos em outro trabalho (Martins, 2007), o objetivo central da educação escolar reside na transformação das pessoas em direção a um ideal humano superior, na criação das forças vivas imprescindíveis à ação criadora, para que seja, de fato, transformadora, tanto dos próprios indivíduos quanto das condições objetivas que sustentam sua existência social. (MARTINS, 2010, p. 15). 
No livro Pedagogia histórico-crítica e luta de classes na educação escolar, Saviani e Duarte (2012) reafirmam e esclarecem a maneira como a pedagogia histórico-crítica, na sociedade capitalista contemporânea, analisa a luta de classes na escola. Trata-se de situar essa pedagogia em um projeto que parte da contradição entre a função específica da escola de socialização do saber sistematizado, por um lado, e, por outro, o fato de o conhecimento ser parte dos meios de produção e sua essência não deve ser plenamente socializada no capitalismo (SAVIANI, 2003).

Essa contradição tem sido trabalhada pelos organismos internacionais a exemplo do BM e a Organização para Cooperação e Desenvolvimento Econômico (OCDE) e posto em prática pelo poder público de modo a assegurar que a escola se afaste de teorias pedagógicas que tenham por principio a bandeira de luta em defesa da socialização dos conhecimentos científicos, artísticos e filosóficos, por serem estes a base indispensável e intencional para a formação e humanização dos indivíduos e que os induza a uma consciência de classe. Esse controle ideológico tem sido exercido pelo Estado pela imposição de um currículo e por uma formação inicial e continuada de professores altamente questionável.

A partir da pedagogia histórico-crítica entendemos o currículo enquanto instrumento intencional e base do trabalho educativo que deve contemplar a universalidade do conhecimento cientifico, ele deve expressar nossas concepções de homem, natureza e sociedade e conforme Saviani explica,

diz respeito, de um lado, à identificação dos elementos culturais que precisam ser assimilados pelos indivíduos da espécie humana para que eles se tornem humanos e, de outro lado e concomitantemente, à descoberta das formas mais adequadas para atingir esse objetivo. (2003 p. 13).

Nesse sentido o currículo ao ser formulado deve-se levar em conta uma seleção intencional de conhecimentos clássicos, os quais devem ser socializados pelos indivíduos. $\mathrm{O}$ conceito de clássico entendido por nós é tudo

aquilo que resistiu ao tempo, tendo uma validade que extrapola o momento em que foi formulado. Define-se, pois, pelas noções de permanência e referência. Uma vez que, mesmo nascendo em determinadas conjunturas históricas, capta questões nucleares que dizem respeito à própria identidade do homem como um ser que se desenvolve historicamente, o clássico permanece como referência para as gerações seguintes que se empenham em apropria-se das objetivações humanas produzidas ao longo do tempo. (SAVIANI \& DUARTE, 2012, p. 31). 
Complementando com o entendimento de Malanchen (2016, p.188) sobre conteúdos clássicos não cotidianos:

(...), o saber sistematizado, não cotidiano, não significa tentar anular o cotidiano do aluno o que, ademais, seria impossível. O objetivo de transmitir ao aluno os conteúdos não cotidianos é a possibilidade de formação de indivíduos que mantenham uma relação cada vez mais consciente com a cotidianidade, mediada pela apropriação das objetivações genéricas para-sí (DUARTE, 2013), como a ciência, a arte e a filosofia. Trata-se, portanto, de abrir possibilidades para que o indivíduo não seja mais conduzido por sua cotidianidade, favorecendo a formação de uma individualidade que hierarquize ou conduza, conscientemente, as atividades da vida cotidiana. A educação escolar, no seu papel de mediadora entre o cotidiano e o não cotidiano, tem em sua tarefa fulcral a transmissão dos conteúdos clássicos, sistematizados, conteúdos estes imprescindíveis à formação do pensamento por conceitos.

Esses elementos culturais que constituem os conteúdos escolares compõem, na verdade, todo um arcabouço cultural necessário à humanização dos indivíduos. Pois se tratam de saberes que passaram pelo processo de objetivação no curso do processo histórico de formação do gênero humano, ou seja, transformaram-se em objetos do conhecimento historicamente acumulado, e que compete à escola e ao professor estimular e mediar o processo de objetivação em cada indivíduo, elevando-os, assim, à condição do gênero humano.

No entanto existe todo um cenário ideológico que tende a secundarizar a importância da escola e de sua ação educativa, na medida em que a população trabalhadora de posse de uma instrução geral poderia questionar a estratificação social e a exploração de uma classe sobre outra, levando, assim, ao acirramento dos embates, contrariando os interesses da burguesia, (SAVIANI, 2005).

Decorre daí o entendimento aqui partilhado de que a burguesia enxerga a escola como um aparelho para a produção de "consensos" e acomodação dos indivíduos na divisão social do trabalho, levando-os a cumprirem pacificamente determinados papéis sociais.

Frente a esses condicionantes, qual será o papel do professor no processo de ensino e aprendizagem? Do ponto de vista expresso no presente artigo e que se apoia nos postulados da pedagogia histórico-crítica, cabe ao professor o papel de direcionar o processo educativo por meio da seleção dos objetos culturais (os conteúdos) e de planejá-la do modo mais adequado, viabilizando as condições práticas para transmissão e assimilação dos conteúdos pelo aluno, estabelecendo critérios ao selecioná-los e sequenciá-los de modo que de forma intencional desenvolva nos alunos a capacidade de se apropriarem da cultura de uma forma geral. Cabe 
também ao professor a tarefa de confrontar o senso comum dos alunos com conhecimento sistematizado e científico produzido pelo gênero humano e que deve ser de propriedade coletiva. (DUARTE, 2016). Conforme Martins, a Pedagogia histórico-crítica, defende um modelo de formação,

[...] que se contraponha ao tipo de saber que assume a forma "valor" e que é vendido e consumido como qualquer outra mercadoria. A ser consumido, até mesmo, sob o emblemático slogan do "aprender a aprender", quiçá próprio de quem nunca pode aprender efetivamente, isto é, que não possibilitou aos indivíduos a conquista da própria autonomia intelectual. E que, igualmente, se contraponha à formação de indivíduos centrada nos ideais de eficácia e otimização das performances, voltada para o desempenho pragmático e quantificável. [...] um modelo de formação alternativo, no qual a construção de conhecimentos se coloque a serviço do desvelamento da prática social, apto a promover o questionamento da realidade fetichizada e alienada que se impõe aos indivíduos. Que supere, em definitivo, os princípios que na atualidade têm norteado a formação escolar, em especial a formação de professores. (MARTINS, 2010, p. 19-20).

No entanto, será que os professores têm conseguido desempenhar esse papel de forma satisfatória? Será que o poder público tem proporcionado condições de trabalho e remuneração adequada para que além de manterem sua sobrevivência elementar, tenham acesso às variadas formas de cultura por meio de livros, teatro, cinema, museus ou viagens? E este mesmo poder público tem desenvolvido políticas de capacitação inicial e continuada com o objetivo de formar professores conscientes de sua importância e de seu papel social, possibilitando acesso aos conhecimentos, quer específicos de sua área de atuação quer gerais ou de fundamentos, para embasar suas aulas?

Alguns sistemas de ensino, a exemplo do sistema paulista que é o maior de todos, têm se orientado no sentido de substituir cursos ou atividades de formação por treinamento em serviço na própria escola, a fim de conter custos, sem falar que estes treinamentos são embasados nas teorias pedagógicas hegemônicas de cunho neoliberal, incorporadas pelo MEC a partir da Lei de Diretrizes e Bases da Educação Nacional (BRASIL, 1996) que, segundo argumenta Derisso (2013, p. 53),

contribuem para a alienação do trabalho docente na medida em que exaltam o conhecimento cotidiano e objetivam a adequação dos alunos à realidade e às exigências do mercado de trabalho. Deste modo descaracterizam o trabalho docente e, consequentemente, a própria escola. Sob a obrigação de aplicar tais orientações, o professor deixa de reconhecer-se na atividade que realiza porque esta se torna adversa e pesarosa.

Não se pode esquecer também que as condições de trabalho, de forma geral no Brasil, às quais os professores estão expostos são de extrema precariedade: salas de aulas 
superlotadas, muitas sem estrutura física adequada, escassez de recursos didáticos, jornadas de trabalhos estafantes e salários irrisórios. Nesse processo de precarização do trabalho docente que aprofunda a desprofissionalização, o professor muitas vezes se vê envolvido em muitas tarefas, deixando o aprendizado do aluno, principal foco de seu trabalho em segundo plano. Todo esse cenário contribui para a criação de um nível de insatisfação e de desprestígio profissional que resulta por afastar os jovens com melhores desempenhos escolares dos cursos de licenciatura, induzindo-os a escolherem profissões mais atrativas do ponto de vista da remuneração e consequentemente com maior reconhecimento social.

Importante esclarecer que nossas ponderações sobre os problemas da carreira docente e da escola pública não tem a intenção de minimizar a responsabilidade dos professores no exercício de sua função, mas chamar a atenção dos leitores para a realidade enfrentada pelos mesmos e para a urgência de desenvolvermos na sociedade uma consciência sobre a importância da educação e da escola pública como instrumento de luta na via da superação da divisão das classes sociais existente na sociedade capitalista.

\section{As concepções pedagógicas hegemônicas em sintonia com o universo ideológico neoliberal}

A importância da educação escolar tem sido asseverada de forma recorrente na atualidade, e historicamente essa incumbência tem sido repassada aos professores, isto posto, as políticas públicas destinados à valorização docente devem levar em conta essa importância que a profissão carrega em si e proporcionar condições adequadas de trabalho e de formação acadêmica consistente seja ela inicial ou continuada.

É no espaço da escola pública que a comunidade escolar tem condições de debater sobre os problemas que afetam a sociedade contemporânea e colocarem-se nos marcos de uma sociedade alternativa, vislumbrando a possibilidade de superação do capitalismo e de suas mazelas.

No entanto sabemos que a escola por si só não irá apontar a revolução socialista como alternativa para a classe trabalhadora libertar-se da opressão, em seu interior, assim como em outros núcleos sociais, existe uma forte carga da ideologia burguesa que defende seus interesses, salvaguardando parte da riqueza intelectual mais apurada em termos artístico, cientifico e filosófico para seu gozo, apartando esse universo cultural dos alunos da escola pública com o argumento de que eles não necessitam dominá-los, uma vez que em sua realidade social não farão uso deles. Entendemos que lutar para que a escola cumpra seu 
papel, que é o de socializar a riqueza intelectual produzida e acumulada pela humanidade, e colocar o aluno frente às contradições existentes na sociedade capitalista, já constitui por si só um ato revolucionário, mesmo que os professores no exercício da ação docente não se apercebam integralmente disso. (DUARTE, 2014). Ainda conforme Duarte (2016, p.138):

[...] a aquisição de conhecimentos, por si só, não supera as enormes barreiras que o capital apõe à efetiva liberdade humana. Essas barreiras só podem ser derrubadas pela luta coletiva pela superação da sociedade capitalista. Por sua vez tal luta só pode ter chances de algum êxito, se estiver orientada por um conhecimento das contradições essenciais que movem a vida social contemporânea, o que demanda o domínio de teorias que cheguem o mais próximo possível da verdade sobre a realidade social. Busca da objetividade e luta ideológica unem-se num mesmo processo.

Importante destacar que existe toda uma pressão ideológica hegemônica no pensamento educacional que perpassa as políticas de formação inicial e continuada de professores, que ao abraçarem concepções teóricas que Duarte (2010, p. 34) denomina de "negativas", remam contra a possibilidade de superação dos antagonismos e da própria sociedade de classes, na medida em que não pregam a possibilidade de resolução dos problemas sociais, mas viram as costas para eles, os naturalizam. Tal naturalização dos problemas e consequentemente das relações sociais respaldam-se em elementos do pragmatismo, no empreendedorismo, na criatividade e no individualismo.

As pedagogias do "aprender a aprender" não constituem novidade do nosso tempo, embasam-se no movimento escolanovista do início do século passado, cujo destaque deve ser dado ao filósofo americano John Dewey que em sua produção acadêmica defendia a ideia de que a educação não deveria restringir-se à transmissão do conhecimento como algo acabado, mas que o saber e habilidades adquiridas pelos alunos pudessem ser integrados à sua vida no cotidiano, ou seja, uma educação adaptativa, pragmática e flexível, logo, distante da reflexão da realidade da sociedade de classes. Essas teorias pedagógicas hegemônicas vislumbram um aluno que seja capaz de construir e ressignificar o conhecimento, tirando, portanto, o foco do ensino aprendizagem do professor, que passa a ser visto como um mediador restrito, um orientador ou facilitador, entre outras tantas possibilidades.

$\mathrm{Na}$ atualidade estas teorias estão em sintonia com o universo ideológico neoliberal na medida em que se transvestem, quando convém, de roupagens adaptativas frente às

\footnotetext{
${ }^{6}$ Já que todas se contrapõem a nossa já declarada concepção de escola e do conceito de conteúdo clássico.

7 São elas: construtivismo, pedagogia de projetos, pedagogia das competências, pedagogia multiculturalista, pedagogia do professor reflexivo, nova e tecnicista.
} 
necessidades ideológicas do pós-modernismo ${ }^{8}$. Não é por acaso que as teorias do aprender a aprender, seguem acompanhadas

\begin{abstract}
de um discurso que alerta para a existência de uma aceleração vertiginosa das mudanças na tecnologia, nas relações de trabalho, nos valores culturais, nas atividades cotidianas, nas relações econômicas e politicas internacionais. Mudança é a palavra da moda. O aluno deve ser preparado para viver numa sociedade em permanente e cada vez mais rápida mudança. O professor deve aprender a conviver com mudanças constantes em seu trabalho e a participar ativamente essas mudanças. Os pesquisadores devem estar dispostos a abandonar seus paradigmas e abraçar os paradigmas da moda. $\mathrm{O}$ trabalhador deve estar sempre disposto a mudar de um trabalho para outro, tendo o desemprego constantemente intercalando essa passagem. O consumidor deve estar sempre apto a comprar um modelo mais novo de um determinado produto, a experimentar outra marca, a sentir necessidade de um novo tipo de produto. O "aprender a aprender" significa educar indivíduos adequados à dinâmica do capitalismo. (DUARTE, 2006 p. 156 -157).
\end{abstract}

Essas teorias compõem o cenário educacional internacional (Relatório Jacques Delors), e estão presentes também nas políticas nacionais, como é o caso da Lei de Diretrizes e Bases (LDB) n ${ }^{\circ}$ 9394/96, dos Parâmetros Curriculares Nacionais (PCNs) Diretrizes curriculares nacionais (DCNs) e na proposta de Base Nacional Curricular Comum (BNCC), que por sua vez alicerçam programas em diversas redes de ensino público em nível estadual e municipal, chegando até os professores na escola. Basicamente as teorias do aprender a aprender enfatizam: a) o aluno pode aprender por si mesmo (autonomia intelectual) sem a intervenção ou transmissão do professor, b) o aluno deve desenvolver um método de aquisição dos conhecimentos por conta própria, c) toda a aprendizagem deve ser considerada a partir dos interesses e necessidades do próprio aluno, d) A educação deve levar em conta o dinamismo da sociedade contemporânea e as necessidades geradas pelas mesmas, transformando os conhecimentos tidos como clássicos em conhecimentos efêmeros. (DUARTE, 2001). De acordo com Duarte (2010) essas teorias pedagógicas têm como principal característica a ausência da perspectiva de superação do modelo social vigente, e por desdobramento a concepção idealista de relações entre educação e sociedade.

Todas essas proposições apontadas e dissociadas de uma reflexão crítica da sociedade são a princípio entendidas como modernas e necessárias para o avanço da educação. No entanto, essas ideias contidas na ideologia das pedagogias hegemônicas pregam, na prática, o

8 Derisso (2010, p.38) assim define o pós-modernismo: O pensamento pós-moderno (ou agenda pós-moderna) implica numa revisão na concepção de ciência cunhada pela modernidade, na negação de que a razão se constitua no instrumento eficaz para a apreensão da realidade e de que por seu intermédio possamos aspirar ao conhecimento da verdade. Sendo assim a possibilidade de interferência sobre a realidade humana e social no sentido de transformá-la conscientemente, ou seja, fazer uma revolução, fica praticamente descartada, possibilitando apenas pequenas interferências ou pequenos arranjos. 
afastamento do professor em relação ao conhecimento elaborado, tanto para si quanto para o aluno, o que só tem legitimado o aviltamento do ensino na escola pública, com o agravante de que para a grande maioria esta se constitui na única porta de acesso ao conhecimento elaborado.

\section{A expansão da formação de professores via a modalidade de EaD}

A análise das políticas educacionais, no que se refere à formação de professores, nos remete à busca da compreensão das prioridades e compromissos que se delineiam e retrata, assim, interesses e funções alocadas a essas políticas no quadro dos constantes padrões de intervenção estatal. Dessa forma, entendemos que as políticas educacionais de EaD para formação de professores também são expressões dos embates travados no âmbito do Estado e nos desdobramentos assumidos por este. Tais embates se situam no contexto de mudanças tecnológicas e, portanto, no reordenamento das relações sociais sob a égide da ideologia da globalização da economia, resultado da política neoliberal que, ao redimensionar o papel do Estado, redireciona as políticas sociais empreendidas por este e, consequentemente, rearticula o papel social da educação.

No âmbito dessas políticas, a diversificação das instituições formadoras de professores, assim como a flexibilização do perfil desses profissionais, constitui ações estratégicas que buscam adequá-los às sempre novas necessidades do mercado de trabalho no atual estágio de racionalidade técnico-científica dos processos profissionais.

Nessa linha de atuação, o governo brasileiro, desde a década de 1990, vem colocando em prática as diretrizes dos OI para o campo educacional, em especial as do BM, que defendem a capacitação prioritariamente em serviço, em detrimento da formação inicial; mecanismos de controle de qualidade externos e internos, com ênfase em uma avaliação das competências dos professores e uso intensivo das novas tecnologias da comunicação e da informação lastreado na modalidade de educação a distância. Isso se torna nítido no processo de expansão tanto na esfera pública, por meio do programa "Universidade Aberta do Brasil/UAB ${ }^{9 ”}$, quanto na rede privada de ensino superior. É preocupante e ao mesmo tempo impressionante como esses cursos de formação à distância cresceram no Brasil, é alarmante

\footnotetext{
${ }^{9}$ Por meio do Decreto $\mathrm{n}^{\circ} 5.800$ de junho de 2006, (BRASIL, 2006) a UAB passou a existir sob os cuidados do MEC, especificamente da Diretoria de Educação a Distância. Esta ligada a Coordenação de Aperfeiçoamento de Pessoal de Nível Superior/Capes, em parceria com a Secretaria de Estado da Educação/Seed, ela representa um sistema integrado por universidades públicas e oferecem cursos de nível superior para a população que alega têm dificuldade de acesso à formação universitária, por meio do uso da metodologia da educação à distância $\mathrm{EaD}$, onde a prioridade é dada para os cursos de Licenciatura.
} 
seu processo de expansão tanto na esfera pública quanto na privada. Sobre a função do professor, de acordo com Evangelista, Et. al (2018, mimeo):

O professor foi atacado em todos os flancos: pela política do livro didático; pelo sistema de avaliação em larga escala; pelo achatamento salarial; pela diminuição dos concursos públicos; pelo excesso de horas-aula; pelo grande número de alunos em sala; pelo não pagamento do piso salarial nacional; pela carência de plano de carreira; pela capitalização dos contratos temporários; pelas diretrizes curriculares; pelo neogerencialismo escolar; pela articulação dos interesses internos e internacionais à formação e trabalho pedagógico; pelo pagamento da formação inicial e continuada em escolas de nível superior não universitárias e, lamentavelmente, pelo esvaziamento teórico-prático de sua formação na modalidade EaD.

Nesse contexto, o que encontramos a partir do ano de 2004 é o ápice da abertura de cursos de graduação a distância em todo o país. Tal crescimento resulta dos incentivos promovidos por OI e Estado por meio das políticas públicas educacionais, que tiveram fortes impulsos a partir da aprovação da Lei de Diretrizes e Bases para a Educação Nacional (LDBEN), Lei $\mathrm{n}^{\circ}$ 9.394, de 1996. Estas políticas realizam um grande movimento pela instauração de um novo modelo de formação superior e visam atender as diretrizes de OI para ajustes em nossa estrutura econômica e social.

As vantagens da $\mathrm{EaD}$, segundo os OI, são diversas. Entre elas, citam a contribuição para ampliar as oportunidades de cursar o ensino superior por meio da ampliação de vagas, permitindo uma educação mais justa, bem como a familiarização do cidadão com tecnologias que estão no seu cotidiano. Desse modo, oferecem-se respostas flexíveis e personalizadas a uma diversidade cada vez maior de tipos de informação, educação e treinamento, por meio da atualização rápida do conhecimento técnico. Com essas recomendações, a EaD é uma alternativa para o Estado no que se refere à possibilidade de expansão do ensino e racionalização de recursos, tendo em vista que a forma de ensino utilizada até então, para esses organismos, não oferecia resultados satisfatórios e, ao mesmo tempo, demandava custos que o Estado considera elevados. (MALANCHEN, 2015).

Os elementos suscitados neste artigo demonstram e autorizam afirmar que tem crescido de maneira incisiva a campanha em prol da utilização da modalidade de EaD no ensino superior. Informações do Censo do Ensino Superior 2013 (CES), produzidos pelo INEP (BRASIL, 2013), e analisados por Evangelista (2016) ratificam nossa argumentação:

No que se refere ao número de cursos (bacharelados, licenciaturas e tecnólogos), verifica-se que dos 32.382 as IES públicas ofereciam $31 \%$ (10.120), cabendo ao setor privado 69\% (22.262). Em relação ao total de matrículas (7.322.925), a diferença entre as ofertas pública e privada era 
maior: 25\% (1.801.479) apenas encontravam-se na rede pública; $75 \%$ (5.521.446) no setor privado.

No caso da área Educação, os números de cursos oferecidos pelas duas categorias administrativas se aproximavam: as IES públicas ofereciam 52\% (4.171) e as privadas $48 \%$ (3.821) dos cursos. De um total de 1.382.257, $43 \%$ (590.067) estavam na rede pública e 57\% (792.190) no setor privado.

Uma outra faceta, relativa ao cruzamento da quantidade de cursos na modalidade de Educação a Distância $(\mathrm{EaD})$ com as esferas administrativas que o oferecem, precisa ser tematizada. Nas IES públicas, dos 4.171 cursos, 91,7\% (3.823) são presenciais; 8,3\% (348) são em EaD. No setor privado, interessantemente, o número de cursos EaD era menor: de um total de 3.821, $6,3 \%$ (240) se ofereciam nessa modalidade, contra 93,3\% (3.581) presencial. O enigma se resolve quando olhamos as matrículas: das 590.067 matrículas na esfera pública, 16\% (94.299), em 2013, eram em EaD. No setor privado, das 792.190 matrículas, 45\% (355.271) eram em EaD. Expõe-se nesse quadro a face cruel do preparo do mestre no Brasil: majoritariamente na rede privada, substantivamente na modalidade $\mathrm{EaD}$.

Os dados comprovam a ideia de que houve um descompromisso proposital e consensual por parte do governo que implica em abrir mão da formação de professores ao mesmo tempo em que favorece o capital privado ampliar suas margens de lucro, aligeirando e barateando a formação não só dos professores, mas também de outros profissionais. Conforme dados de Evangelista, et al. (2018, mimeo):

Se a questão em tela revela-se grave, a tendência é que se intensifique em razão do Decreto n $^{\circ}$ 9.057, de 25 de maio de 2017 (BRASIL, 2017b), que altera determinações substantivas da Lei de Diretrizes e Bases da Educação Nacional (LDBEN), Lei 9.394, de 20 de dezembro de 1996 (BRASIL, 1996). Com esta norma, o (des)governo de Michel Temer (2016-?), do Partido do Movimento Democrático Brasileiro (PMDB), concedeu às IES maior autonomia para a abertura de novos polos de $\mathrm{EaD}$, prescindindo de autorização prévia do Ministério da Educação, ademais de poderem se conformar como instituições vocacionadas unicamente para o ensino nessa modalidade

O que se constata é que a ideia de afastar os professores dos cursos presenciais se deve ao fato de que os responsáveis pela elaboração de políticas públicas para a formação de professores não os almejam como um profissional que necessite dominar conhecimentos científicos, artísticos e filosóficos, já que atuam em escolas públicas de formação básica frequentados em sua grande maioria por filhos da classe trabalhadora.

Diante dos fatos, é evidente que as ideias dos OI aliadas as da burguesia, caminham em sintonia no sentido de garantir o lucro e a formação de mão de obra desqualificada e alienada. Segundo Freitas (2014, p. 427):

A formação de professores é o alvo principal das atuais políticas educativas, principalmente no âmbito dos estados e municípios. Como área estratégica para o capital, por agregar valor ao seu processo de exploração e 
acumulação, vem mobilizando em toda a América Latina articulações entre empresariado e poder público para uma intervenção mais direta na educação pública, especialmente nas áreas de gestão, currículo, formação, avaliação e financiamento.

Ainda, essas políticas têm, nos programas de EaD, sua proposta para a formação de professores. Ademais, tal iniciativa é fundamental na reformulação ou no "desmonte" do ensino público superior. Como assinalamos, trata-se de priorizar a formação de professores da educação básica, particularmente do ensino fundamental, mediante programas "aligeirados", preferencialmente em serviço, e criar condições favoráveis nas instituições públicas para o investimento dos setores privados, por meio do ensino a distância.

A expansão da educação superior à distância no Brasil, traduzida predominantemente em cursos de formação de professores, como se vê, tem sido norteada pela orientação dos OI, segundo a qual a dinâmica a ser aplicada nos projetos de formação de professores deve obedecer à mesma lógica do mundo da produção e da circulação das mercadorias. Para isso, assinalam que as reformas educacionais a serem implementadas precisam estar cada vez mais centradas no aperfeiçoamento das habilidades dos professores. (MALANCHEN, 2015).

O discurso disseminado pelas políticas educacionais da democratização, que justifica a implementação da EaD no ensino superior e na formação docente, expressa a ideologia segundo a qual devemos acreditar que por meio da educação podemos diminuir ou terminar com as desigualdades sociais. Entretanto, não é demais reafirmar que as desigualdades que essa modalidade pretende suprimir não foram produzidas no âmbito da educação. Do mesmo modo, não será nesse âmbito que tais questões encontrarão solução.

Segundo nossa perspectiva, a desigualdade socioeconômica não tem no terreno educacional seu lócus de produção e tampouco de superação. Contrariamente, essa modalidade de ensino colabora para a perenização das desigualdades, até mesmo ampliandoas mediante as diferenças impostas pela formação na $\mathrm{EaD}$. O que temos com esse discurso é a expansão em grande escala da formação docente à distância, que promove a desintelectualização do profissional (SHIROMA, 2003), ancorando sua formação na epistemologia da prática e na individualidade, afastando qualquer possibilidade de uma formação teórica mais sólida e coletiva.

Pelo discorrido, concluímos que o interesse na democratização do acesso à educação superior, via EaD, além de criar uma ilusão de que todos, por meio dela, podem melhorar suas vidas, carrega outra intenção: a de formar mão-de-obra especializada para a nova fase de acumulação do capital que exige trabalhadores capacitados tecnicamente, criativos, eficientes 
e adaptáveis. Em outros termos, a educação passa a ser vista como um instrumento para o desenvolvimento econômico, para o ajustamento dos indivíduos ao chamado mercado de trabalho, deixando-se em segundo plano a questão da educação como instrumento de emancipação humana, de participação, de interferências nas questões políticas, de expressão de pontos de vista sobre o modo de condução da coisa pública.

Sendo assim, além de baratear a formação do professor por meio da EaD, na qual são contratados tutores presenciais e virtuais para operacionalizar o programa, investe-se em menos funcionários, menos espaço físico e menos tempo presencial. Também é possível modelar um novo perfil de professor, técnico e politicamente inofensivo. Neste contexto, efetivam-se propostas e políticas de formação de um docente desintelectualizado, pouco habituado ao exercício do pensamento. Para Evangelista Et al. (2018, mimeo) isso representa:

O massacre intelectual de parcelas imensas da juventude, direta ou indiretamente, mediante o empobrecimento do conteúdo intelectual de sua qualificação tem em vista cancelar - tentativa de resto frustrada - as condições mínimas para que possam exercer plenamente seus potenciais reflexivos, críticos, analíticos e organizativos [... ] Esse percurso histórico, agravado após 2006-2007, não está incorporado apenas na venda e revenda de matrículas e diplomas; mostra as vísceras de uma íntima e essencial articulação entre o Estado e o capital na qual a formação humana precisa ser obstada. Os hediondos direcionamentos políticos do capital - providenciados todos os dias - têm precipitações funestas para a nossa escolarização, o nosso pensamento, a nossa existência.

Com base nessas reflexões, podemos chegar à conclusão de que a democratização da formação docente por meio da $\mathrm{EaD}$ pretende alcançar três objetivos: o primeiro é o de baratear o custo da formação docente; o segundo é o de capacitar tecnicamente e habilitar legalmente os professores; o terceiro é o de despolitizar essa formação e, com isso, torná-los pragmáticos e diminuindo-lhes a capacidade de intervenção consciente, assim sendo, isto também será reproduzido em seus alunos.

\section{Considerações Finais}

A exposição realizada ao longo deste artigo demonstra que, sob a hegemonia neoliberal, o papel do Estado brasileiro foi redefinido: de executor ou de prestador direto dos serviços sociais para regulador destes. Os princípios da reforma do Estado - eficiência, competitividade, qualidade e flexibilidade - nortearam a reforma educacional, expressando a articulação entre ambas. 
No âmbito dessas políticas, a "flexibilização" das instituições formadoras de professores, assim como do perfil destes profissionais, constituiu ação estratégica no sentido de adequá-los às novas necessidades do mercado de trabalho e no estágio de racionalidade técnico-científica dos processos produtivos. Mandeli (2014, p.178) descreve com clareza o perfil de professor desejado pelos OI:

professor pragmático, reflexivo em relação a sua ação, solidário, eficiente e eficaz nos processos educativos, preservador e promotor da coesão social, responsabilizado pelos resultados das avaliações dos alunos e pela qualidade da educação, responsável pelas reformas na escola, preparado para formar indivíduos com o conhecimento e as habilidades que necessitam para as demandas atuais. Além disso, com conhecimentos, competências e qualidades pessoais que gerem inovações; que saibam lidar com questões relacionadas à diversidade cultural, gênero, sexualidade, preservação do meio ambiente, ética e cidadania; solucionador de problemas, até mesmo econômicos, e mobilizador de recursos afetivos e cognitivos, "principais peças da economia das sociedades modernas".

Entende-se, portanto que, a concepção de política para a formação de professores da educação básica tem-se assentado na defesa: da capacitação, prioritariamente, em serviço, em detrimento da formação inicial; de mecanismos de controle de qualidade externos e internos, com ênfase na avaliação das "competências", com vistas à certificação, e das novas tecnologias da comunicação e da informação, incorporadas via EaD.

Ademais, tal iniciativa é fundamental no "desmonte" do ensino público superior. Como assinalamos, trata-se de priorizar a formação de professores mediante programas “aligeirados", preferencialmente em serviço, e criar condições favoráveis nas instituições públicas para o investimento dos setores privados, por meio do ensino a distância. Ainda para Mandeli (2014, p.232):

Na configuração das políticas estudadas, percebemos mudanças no processo formativo do professor. A formação se distancia da produção do conhecimento, pois é disseminada uma aprendizagem flexível, distribuída e rápida. Há um privilegiamento da aprendizagem e um apagamento do ensino, procurando romper-se a unidade existente entre ensino e aprendizagem (BARRETO, 2011). Isso atinge a relação professor-aluno, secundariza o papel do primeiro e impõe ao segundo a autoaprendizagem. Um discurso fetichizado sobre as TIC fundamenta estas ideias, como se fossem capazes de ligar o aluno de forma direta, ou mesmo automática, com o conhecimento.

O projeto de formação de professores que, até então, conseguiu a hegemonia política e cultural, inscreve-se no movimento de empobrecimento do trabalho e da formação docente. Para Evangelista Et. al (2018, mimeo): 
A qualificação de professores transformou-se, como dito, em primoroso alvo de grandes escolas privadas de formação superior. Dados de 2016 (BRASIL, 2017a) ilustram o contexto no qual aspirantes ao magistério foram certificados: 67,2\% (160.401) dos estudantes passaram por IES privadas; $32,8 \%$ (78.518) por IES públicas. O que tais dados não mostram por si mesmos são as ameaças decorrentes da progressiva submissão das instituições e dos conteúdos da qualificação do magistério às novas formas de oferta sob o comando do capital, especialmente nas escolas particulares.

Nossas conclusões demostram que a EaD cumpre um papel prioritário no projeto educacional de uma sociedade em que imperam os interesses do capital internacional. Esta modalidade realiza a formação ou conformação de professores de maneira precária e rápida, com um conhecimento político restrito e pragmático. Consolida uma formação/conformação do professor com uma sociabilidade instrumental.

Torna-se necessário uma mobilização nacional que discuta a educação pública com quem de fato conhece e se utiliza da escola pública, a partir de seus entraves e avanços, das necessidades e expectativas de seus usuários e de seus docentes, tendo em mente a dimensão social que a escola e a educação pública têm, aliando o conhecimento socialmente construído pela humanidade rumo à construção de uma nova sociedade. Uma tarefa árdua, mas necessária.

Desse modo é incondicional que a formação inicial de professores seja responsabilidade das universidades públicas, no modelo presencial de ensino, que privilegia o debate, a reflexão crítica, a perspectiva humanista e a indissociabilidade entre ensino, pesquisa e extensão. Isto posto, a pedagogia histórico-crítica, contrariando as pedagogias relativistas, hegemônicas na sociedade capitalista contemporânea, continua sua luta, buscando contribuir para:

uma abordagem marxista que supere os limites do Iluminismo sem negar o caráter emancipatório do conhecimento e da razão; que ultrapasse os limites da democracia burguesa sem negar a necessidade da política; que transponha os limites da ciência posta a serviço do capital sem, entretanto, negar o caráter indispensável da ciência para o desenvolvimento humano; que supere a concepção burguesa de progresso social sem negar a possibilidade de fazer a sociedade progredir na direção de formas mais evoluídas de existência humana. Tudo isso se traduz, no que diz respeito ao campo educacional, na defesa de uma pedagogia marxista que supere a educação escolar em suas formas burguesas sem negar a importância da transmissão, pela escola, dos conhecimentos mais desenvolvidos já produzidos pela humanidade (DUARTE, 2010, p. 115).

Reafirmamos os fundamentos teóricos que embasam este artigo de que a escola e a atividade docente têm papéis históricos a cumprir: formar sujeitos conscientes de seus 
direitos, armados filosoficamente para o debate e para a luta. Nesse sentido se faz necessário que professores tenham uma formação sólida que só será possível dentro das universidades públicas que trabalhem com projetos pedagógicos com a perspectiva social de formação de professores e ser humano pautado numa perspectiva de superação do modelo social existente e não de meras adaptações ou pequenas reformas. A defesa da Escola pública, laica e gratuita, é a nossa luta!

\section{REFERÊNCIAS}

BRASIL. Secretaria Da Educação Fundamental. Parâmetros Curriculares Nacionais. Brasília: MEC/SEF, 1998. Disponível em:

$\leq$ http://portal.mec.gov.br/index.php?option=com_docman\&view=download\&alias=15548-dc-n-educacao-basica-nova-pdf\&Itemid=30192>. Acesso em: 01/12/2016.

BRASIL. Ministério da Educação, Secretaria de Educação Básica, Diretoria de Currículos e Educação Integral. Diretrizes Curriculares Nacionais Gerais da Educação Básica. Brasília: MEC, SEB, DICEI, 2013. Disponível em: $<$ http://portal.mec.gov.br/index.php?option=com docman\&view=download\&alias=15548-d-c-neducacao-basica-nova-pdf\&Itemid=30192/. o > . Acesso em: 01/12/2016.

BRASIL, Presidência da República do. Medida Provisória n 746, de 22 de Setembro de 2016: Institui a Política de Fomento à Implementação de Escolas de Ensino Médio em Tempo Integral, altera a Lei $\mathrm{n}^{\circ}$ 9.394, de 20 de dezembro de 1996, que estabelece as diretrizes e bases da educação nacional, e a Lei n$^{\circ} 11.494$ de 20 de junho 2007, que regulamenta o Fundo de Manutenção e Desenvolvimento da Educação Básica e de Valorização dos Profissionais da Educação, e dá outras providências. Disponível em: $<$ http://portal.mec.gov.br/index.php?option=com_docman\&view=download\&alias $=48601$ mp-746-ensino-medio-link-pdf\&category slug=setembro-2016-pdf\&Itemid=30192>. Acesso em: 01/12/2016.

BRASIL. Lei de Diretrizes e Base da educação Nacional 9394 de 20 de dezembro de 1996. Brasília, 1996. Disponível em: <https://www.planalto.gov.br/ccivil_03/Leis/L9394.htm>. Acesso em: 01/12/2016.

DERISSO, Jose Luis. Luta de classes, trabalho docente e pedagogia histórico-crítica na educação escolar. Germinal: Marxismo e Educação em Debate, Salvador, v. 5, n. 2, p. 47-58, dez. 2013. Dez. 2013.

DELORS, Jacques. Educação: um tesouro a descobrir. 8. Ed. São Paulo: Cortez; Brasília, DF: MEC: UNESCO, 2003.

DUARTE, Newton. As pedagogias do "aprender a aprender" e algumas ilusões da assim chamada sociedade do conhecimento. Revista Brasileira de Educação, Rio de Janeiro: ANPED, n. 18, p. 35-40, set.- dez. 2001. 
Vigotski e o "Aprender a Aprender": Crítica às Apropriações Neoliberais e PósModernas da Teoria Vigotskiana. Campínas: Autores Associados. 2006.

. O Debate Contemporâneo das teorias Pedagógicas. MARTINS, L.M.; DUARTE, N., (org.). Formação de professores: limites contemporâneos e alternativas necessárias [online]. São Paulo: Editora UNESP; São Paulo: Cultura Acadêmica, 2010.

A formação humana na perspectiva histórico-ontológica. In: SAVIANI, Dermeval; DUARTE, Newton (Org.). Pedagogia histórico-crítica e luta de classes na educação escolar. Campinas: Autores Associados, 2012.

A Individualidade Para Si: Contribuição a uma teoria histórico-crítica da formação do individuo. Edição Comemorativa. Campinas, SP: Autores Associados, 2013.

A pedagogia histórico-crítica no âmbito da história da educação brasileira. In: PINHEIRO, A.C.F.; CURY, C.E.; ANANIAS, M. (Org.). Histórias da Educação brasileira: experiências e peculiaridades. João Pessoa: Editora da UFPB, V.1, p. 29-50. 2014.

Os Conteúdos Escolares e a Ressurreição dos Mortos: contribuição à teoria histórico-crítica do currículo. Campinas, SP: Autores Associados, 2016.

EVANGELISTA, Olinda. Formação de professores: um bem mercadejável? Florianópolis, SC: UFSC, 2016.

EVANGELISTA, Olinda; SEKI, Allan kenji; SOUZA, Artur Gomes. Formação docente no Brasil pós-2000: Lances de um massacre intelectual. Florianópolis, SC: UFSC, 2018.

MALANCHEN, Julia. Cultura, conhecimento e currículo: Contribuições da Pedagogia Histórico-Crítica. Campinas, SP: Autores Associados, 2016.

Políticas de Formação de Professores a distância no Brasil: uma análise crítica. Campinas, SP: Autores Associados, Coleção Formação de Professores. 2015.

MANDELI, Aline de Souza. Fábrica de professores em nível superior: a Universidade Aberta do Brasil (2003-2014). Dissertação de mestrado, defendida no Programa de pósgraduação da UFSC, 2014.

MARTINS, L.M., and DUARTE, N., (orgs). Formação de professores: limites contemporâneos e alternativas necessárias [online]. São Paulo: Editora UNESP; São Paulo: Cultura Acadêmica, 2010. 191 p. ISBN 978-85-7983-103-4. Available from SciELO Books .

OLIVEIRA, Dalila Andrade. A Reestruturação do Trabalho Docente: precarização e Flexibilização. Educação e Sociedade. Campinas, vol. 25, nº. 89, 2004.

SALDAÑA, Paulo. Maioria dos estudantes de oito anos não sabe ler nem fazer conta direito. UOL Folha de S. Paulo. Disponível em: $<$ http://www1.folha.uol.com.br/educacao/2017/10/1930040-metade-dos-alunos-de-8-anostem-nivel-insuficiente-de-leitura-e-matematica.shtml >. Acesso em 08/03/2018. 
SHALOM, David. Brasil levará ao menos 10 anos para sair de patamar indigente na Educação. Último Segundo (Blog). São Paulo, 14/02/2016. Disponível em:

<http://ultimosegundo.ig.com.br/educacao/2016-02-14/brasil-levara-ao-menos-10-anos-parasair-de-patamar-indigente-na-educacao.html> . Acesso em: 12/09/2016.

SAVIANI, Dermeval. Escola e Democracia. 36 ${ }^{\mathrm{a}}$ ed. Campinas, SP: Autores Associados, 2003.

Pedagogia Histórico-Crítica: Primeiras Aproximações. $9^{a}$ ed. Campinas/Autores Associados, 2005. 